\title{
(RE)PENSANDO O ENSINO JURÍDICO POR MEIO DAS PRÁTICAS DE STORYTELLING: O EXEMPLO DO JÚRI
}

\section{(RE)THINKING THE LEGAL EDUCATION THROUGH THE STORYTELLING PRACTICES: THE EXAMPLE OF THE JURY}

\author{
${ }^{1}$ Tamer Fakhoury Filho \\ ${ }^{2}$ Frederico de Andrade Gabrich
}

\section{RESUMO}

É preciso (re)pensar o ensino jurídico valendo-se de novas metodologias. Isso pressupõe a mudança do modelo mental dominante no ensino e na prática do direito (ainda essencialmente fundado no conflito e no processo judicial). Um novo modelo pode ser implementado com a análise estratégica do Direito e com o storytelling. $\mathrm{O}$ storytelling na sala de aula e na prática profissional é um dos caminhos viáveis para a implementação dessas mudanças. Como o storytelling já é usado no Tribunal do Júri, pode também ser usado em outros âmbitos profissionais, e aprimorado como ferramenta de ensino do direito, independentemente da disciplina.

Palavras-chave: Ensino jurídico, Storytelling, Tribunal do júri, Análise estratégica do direito, Metodologia de ensino

\begin{abstract}
It is necessary to (re)think legal education using new methodologies. This requires changing the dominant mindset in teaching and practice of law (still essentially based on conflict and judicial proceedings). A new model can be implemented with the strategic analysis of the law and the storytelling. The storytelling in the classroom and in professional practice, is one of the viable ways to implement these changes. As the storytelling is already used in the jury, it can also be used in other professional fields and enhanced as a tool teaching of law, regardless of discipline.
\end{abstract}

Keywords: Legal education, Storytelling, Jury court, Strategic analysis of law, Teaching methodology

\footnotetext{
${ }^{1}$ Mestranda em Instituições Sociais, Direito e Democracia na Universidade FUMEC, Belo Horizonte - MG (Brasil). E-mail: tamer.fak@gmail.com

${ }^{2}$ Doutor em Direito pela Universidade Federal de Minas Gerais - UFMG, Belo Horizonte - MG (Brasil). Professor da Universidade, FUMEC, Belo Horizonte - MG (Brasil). E-mail: frederico.gabrich@gmail.com
} 


\section{INTRODUÇÃO}

Pensar (e repensar) o ensino jurídico é uma exigência contemporânea. A integração e associação entre educadores, educandos e instituições deve se dar de modo simbiótico, exigindo desses atores uma ação preeminente que dê ensejo a benefícios mútuos e trocas de experiências.

O Direito é reconhecidamente uma ciência social aplicada, que remete a um diálogo entre prática e teoria. Nesse sentido, exige uma análise estratégica, um pensar jurídico estratégico voltado à realização plena e eficaz dos objetivos das pessoas.

No entanto, a educação jurídica tem acontecido tradicionalmente por meio da utilização de um modelo pedagógico essencialmente instrucionista, conteudista, conceitualista, focado no professor. Calcado principalmente na metodologia das aulas expositivas, utiliza uma abordagem exageradamente dogmática e estática, que acaba por mitigar o verdadeiro potencial da educação andragógica, crítico-reflexiva e transformadora.

Essa situação revela a necessidade da quebra de paradigmas, para o enfrentamento dos desejos e das reais necessidades profissionais e acadêmicas dos alunos dos cursos jurídicos do século XXI. É necessária a mudança do modelo mental dominante no ensino e na prática do Direito (ainda muito fundado no conflito e no processo judicial), que pode ser implementada por meio da Análise Estratégica do Direito e da aplicação de técnicas de comunicação mais conectadas com os tempos atuais.

Dentre os conceitos, metodologias, técnicas e instrumentos "inovadores" à disposição dos educadores, em especial no Direito, apresenta-se o storytelling. Utilizada estrategicamente no plano das organizações, essa ferramenta de comunicação, que pode traduzida como a arte de narrar histórias ${ }^{1}$, é (ou pode ser) transportada para o campo educacional como verdadeiro facilitador da aprendizagem.

No campo do Direito, muitos profissionais já fazem uso do storytelling, seja em sala de aula, seja na prática da advocacia.

No ensino jurídico, destacam-se as aulas de Direito Penal, ramo do qual emerge uma gama significativa de possibilidades de uso do storytelling, técnica que nem sempre adequadamente explorada com todo seu potencial em outras disciplinas.

\footnotetext{
1 Nesta pesquisa, os termos história e estória remetem, ambos, à descrição de situações reais e fictícias, não havendo distinção de ordem conceitual entre os vocábulos em questão.
} 
No âmbito profissional do Direito, o Tribunal do Júri é exemplo de aplicação real e efetiva desse modelo estratégico de comunicação, qual seja: o storytelling. Caracterizado pela técnica de contar histórias com poder de persuasão, contextualização e integração, essa ferramenta permite ao operador prático do Direito, em especial no universo do Júri, atingir seus objetivos, com resultados positivos e benéficos.

Entretanto, não se pode distorcer a questão. Considerando o exemplo do Tribunal do Júri, é preciso que a prática jurídica traga sua contribuição para o espaço acadêmico, sem afastar as inovadoras metodologias e ferramentas de comunicação efetivas já disponíveis.

O diálogo entre a prática e a teoria jurídica deve se dar contínua e permanentemente, e as técnicas utilizadas no plano teórico ou no plano prático constituemse como exemplos recíprocos a serem utilizados nos dois espaços.

Com fundamento no método dedutivo e baseado nos referenciais teóricos estabelecidos principalmente pela Análise Estratégica do Direito, a partir do pensamento capitaneado por Frederico Gabrich e pelo storytelling examinado por Gyslaine Avelar Matos, esta pesquisa propõe demonstrar, a partir do exemplo do Júri, as amplas possibilidades de aprimoramento das metodologias de ensino jurídico contemporâneas.

\section{A NECESSIDADE DE (RE)PENSAR O ENSINO JURÍDICO}

Ensinar é uma arte, uma tarefa nobre, um desafio que se perfaz ao longo do tempo, da história da humanidade, da civilização.

A educação (lato sensu) é direito fundamental previsto na Carta da República de 1988, e permeia todo o texto constitucional vigente. Entretanto não é relevante esmiuçar, neste trabalho, o conteúdo em questão, mas apenas apontar sua previsão normativa.

A prática de educar abrange cenários e atores diversos, cuja multiplicidade e heterogeneidade são características marcantes. Num espaço voltado ao saber, educadores e educandos interagem (embora nem sempre) de modo a contribuir para a formação do ser e das coisas.

Docente, professor(a), orientador(a), instrutor(a); muitas são as denominações utilizadas, porém a verdadeira qualidade distintiva da pessoa que ocupa essa posição privilegiada na sociedade está em sua atuação e nos resultados de seu trabalho, não na nomenclatura que recebe. 
Do mesmo modo, discente, aluno(a), orientando(a), instruído(a), dentre outras terminologias, designam o destinatário (não único) dessa experiência prática recíproca, qual seja, a do ensino, da aprendizagem.

Nesse campo de ação, a formação individual do ser humano se dá diariamente. Essa construção está associada às experiências que cada ser carrega, por sua vez relacionadas à religião, ideal político, conjectura socioeconômica, realidade familiar e pessoal, dentre outros aspectos que formam uma matriz particular a ser considerada.

$\mathrm{O}$ ideal seria que esses agentes - docente e discente - se associassem reciprocamente, de modo simbiótico, dando ensejo a benefícios mútuos, trocas de experiências e de conhecimento.

Arquitetar ambientes favoráveis para que ocorra esse fenômeno é fundamental, o que não necessariamente acontece como regra, infelizmente. No entanto, é forçoso sopesar e aceitar que no espaço de aprendizagem não predominam unicamente momentos bons, há também momentos de frustração, de imposição da rotina e de conteúdos excessivamente dogmáticos e programáticos, indispensáveis e inarredáveis da realidade do ensino.

Escola, faculdade, universidade, espaço virtual; enfim, os recintos que recebem esses atores, também independentemente do nome que recebem, são essencialmente "sítios" coletivos de ensino, que acolhem bagagens de distintas ordens relacionadas às histórias de vida de educadores e educandos, o que, conforme dito, deve ser levado em consideração por essas instituições (públicas ou privadas), extremamente (algumas, unicamente) preocupadas com o conteúdo programático, e tão somente isso.

Sendo o Direito uma ciência social aplicada, seja no âmbito do ensino fundamental, do ensino médio, da graduação, da pós-graduação lato ou stricto sensu; o educando, de algum modo, tem contato com "matérias" e "conteúdos" relacionados ao mundo jurídico. Estes fazem parte de sua vida, de seu cotidiano e apontam para experiências, por exemplo, no palco das relações interpessoais, no plano familiar, das relações de consumo, entre outras circunstâncias reguladas pelo ordenamento jurídico. 
Seja qual for essa experiência, por meio de reportagens, palestras, seminários, atividades extraclasse, dentre outras, o Direito está ao alcance de todos, é direcionado e atinge grupos de pessoas que compõem esse panorama, que precisam ser instigadas em direção à produção do saber, em especial, alunos contemporâneos do curso de Direito² .

Não obstante os fatos descritos, o atual ensino jurídico (graduação e pósgraduação)

que se pratica no Brasil carece de reflexão crítica ${ }^{3}$; (re)pensá-lo é um imperativo hodierno, principalmente no que tange ao diálogo (exigível e não verificável a contento) entre prática e teoria.

O sistema de ensino do Direito, em grande parte, está inserido em um ciclo vicioso que desconsidera totalmente a busca da qualidade, em prol da quantidade e dos resultados “palpáveis” e "mensuráveis" (GABRICH, 2010, p. 275).

Traçar um diagnóstico que possibilite a identificação e a implementação de novas metodologias voltadas ao saber jurídico, considerando aspectos não só de ordem objetiva ou estatística, mas também subjetiva e qualitativa, aquilatando assim valores intrínsecos a um pensar jurídico estratégico ${ }^{4}$, é fundamental no mencionado sistema.

Nesse sistema encontram-se as instituições de ensino jurídico. Inês Maria de Carvalho

Campolina assim define:

\footnotetext{
2 Os alunos contemporâneos demandam maiores estímulos, com métodos de educação novos e atualizados com a nova realidade que criou novas perplexidades. Nesse panorama, também requerem a participação de outros atores coadjuvantes. Desse modo, verifica-se o alinhamento e aplicabilidade da teoria em questão com a necessidade de se (re)pensar o ensino jurídico.

3 Paulo Freire, um dos maiores intelectuais do século XX, desenvolveu uma teoria ou compreensão ético-crítico- política da educação, alicerçada no diálogo e na conscientização. Em sua obra "Pedagogia da Autonomia: saberes necessários à prática educativa", o autor expõe um raciocínio interessante: a reflexão crítica sobre a prática se torna uma exigência da relação teoria/prática, sem a qual a teoria pode ir virando blá-blá-blá e a prática, ativismo (FREIRE, 2015, p. 24).

${ }^{4}$ Frederico de Andrade Gabrich desenvolveu a tese de uma análise estratégica do Direito. De acordo com essa concepção: é necessária uma nova maneira de encarar o Direito e as normas jurídicas, tornando-se fundamental a realização de um pensar jurídico estratégico, direcionado para a estruturação dos objetivos traçados pelas pessoas, empresas e Estado (GABRICH, 2010, p. 29). Ao apreciar e refletir sobre essa explanação, numa perspectiva voltada para esta pesquisa, entende-se por pessoas os educadores e educandos, assim como por empresas, as instituições de ensino, e por Estado, as organizações que o representam; tudo isso sem desconsiderar outros atores coadjuvantes que compõem esse panorama. Desse modo, verifica-se o alinhamento e aplicabilidade da teoria em questão com a $\begin{array}{lllllll}\text { necessidade } & \text { de } & \text { se } & \text { (re)pensar } & \text { o } & \text { ensino } & \text { jurídico. }\end{array}$
} 


\begin{abstract}
A instituição de ensino constitui-se de uma organização multiculturalista, inserida em vertentes administrativas, legais e pedagógicas, com diferentes níveis cognitivos e culturais que se somam e se entrelaçam na finalidade de obter a excelência na formação do ser humano e na responsabilidade social mediante instrumentos hábeis a dar suportes eficientes para alicerçar a educação jurídica. (CAMPOLINA, 2014, p. 3).
\end{abstract}

No Brasil, muitas das instituições de ensino superior de Direito que compõem esse sistema não contribuem de modo efetivo para transformar o quadro em que se encontram. Não são elaborados ou efetivados projetos pedagógicos inovadores; é o que constata Frederico de Andrade Gabrich, ao dispor que:

[...] as instituições de ensino superior não desenvolvem, em regra, nenhum projeto de requalificação dos seus profissionais, ou a definição de um projeto pedagógico voltado para o desenvolvimento eficaz de novas práticas de ensino, pesquisa e extensão. $\mathrm{Na}$ maioria dos casos, inclusive, o projeto pedagógico é um documento que habita o mundo das formalidades, sem qualquer correspondência com ações eficazes ou voltadas realmente para o aperfeiçoamento do ensino superior de Direito. (GABRICH, 2010, p. 275).

Esse fato não poderia (ou deveria) servir de obstáculo para uma postura proativa do educador. O professor de Direito (e de outras áreas do conhecimento) deveria se valer de novos modelos para que sua atividade pudesse ser realizada de modo mais efetivo e eficaz, de acordo com as exigências e necessidades dos educandos, sem, contudo, ofender as ultrapassadas premissas legais impostas por projetos antiquados, mas ainda em vigor.

No entanto, a educação jurídica tem ocorrido tradicionalmente por meio de um modelo instrutivista e dogmático, cuja finalidade é o repasse de conteúdo por meio de aulas expositivas calcadas principalmente nos textos legais, exigindo-se do aluno a memorização desse conteúdo, e deixando o professor em uma posição estática, sem qualquer preocupação explícita com a integração desses agentes, o que acaba mitigando o potencial do saber e da aprendizagem que poderia ser efetivado a partir de outros moldes.

De acordo com Simone Cristina Mussio, Valéria Cristiane Validório e Véra Maria Ferro Merlini (2014), no modelo instrutivista, o aluno é visto como um sujeito passivo, que apenas recebe as instruções de um professor que transfere o conteúdo por ele adquirido.

Paulo Freire critica esse modelo ao tecer as seguintes considerações: 
[...] ensinar não é transferir conteúdo a ninguém, assim como aprender não é memorizar o perfil do conteúdo transferido no discurso vertical do professor. Ensinar e aprender tem que ver com o esforço metodicamente crítico do professor de desvelar a compreensão de algo e com o empenho igualmente crítico do aluno de ir entrando como sujeito em aprendizagem, no processo de desvelamento que o professor ou professora deve deflagrar. (FREIRE, 2015, p. 116).

Observa-se, então, que o mencionado autor entende que "ensinar não é transferir conhecimento, mas criar as possibilidades para a sua produção ou a sua construção" (FREIRE, 2015, p. 24).

Nas palavras de Normam José Solórzano Alfaro, a forma tradicional de "ensino do Direito" consiste na transmissão quase unilateral de uma série de estratégias e táticas para o manejo eficiente da linguagem jurídica e do sistema burocrático (ALFARO, 2013, p. 423). Em regra (com raras exceções), não há dialogicidade ou integração entre professores e alunos.

Já a concepção construcionista dá enfoque ao "conhecimento" de modo mais interativo. $\mathrm{O}$ educador participa do processo de aprendizagem de forma mais ativa, fazendo uso de instrumentos e tecnologias para aprender e para ensinar. Um maior dinamismo caracteriza esse tipo de investida. Entretanto, não se trata de um modelo completamente hábil a atender às exigências e desejos contemporâneos da educação superior, em especial no Direito.

Isso porque, nas palavras de Eduardo Moura da Costa:

\begin{abstract}
Para o construcionismo a construção do conhecimento pelo aluno deve estar relacionado com o seu interesse e deve responder a uma demanda de seu contexto social, seja uma obra de arte, um relato de experiência ou um programa de computador (Valente, 2005). O construcionismo foi criado pelo matemático norte americano Seymour Papert. O construcionismo eleva ao máximo a noção de construção do conhecimento, se limitando ao contexto dos educandos. Essa perspectiva não levaria em conta as diferenças de classe no processo de construção do conhecimento "contextualizado". (COSTA, 2013, p. 5)
\end{abstract}

É impreterível quebrar paradigmas, inovar ${ }^{5}$. Sem abandonar totalmente os critérios tradicionais do ensino jurídico, faz-se necessária uma mudança bastante radical ou uma sensível evolução das metodologias tradicionalmente aplicadas ao ensino jurídico (GABRICH, 2010, p. 27).

$\mathrm{Na}$ elaboração de conteúdos de disciplinas, além de adotar as diretrizes curriculares fixadas, deve-se ponderar o desenvolvimento de projetos que valorizem uma via de mão 
dupla, sob a ótica do educador e do educando, identificando atributos e desejos dos destinatários do saber.

A realidade da educação jurídica impõe que se observe e faça uso de um novo modelo, uma nova abordagem (sem eliminar os demais modelos, que podem e devem trabalhar em conjunto, pois não se anulam, mas se complementam), qual seja, construtivista ${ }^{6}$.

Essa abordagem construtivista é mais ampla e permite a utilização de novas metodologias voltadas à promoção da análise crítico-reflexiva por parte do educando acerca do conteúdo recebido, além do desenvolvimento de suas habilidades, por meio de experimentos voltados à integração de todos envolvidos nesse contexto, com participação ativa e efetiva, de modo a considerar aspectos da vida pessoal, acadêmica e social.

Educadores de todo o país vêm utilizando, mesmo sem o devido suporte institucional, conceitos, metodologias, técnicas e instrumentos inovadores que se encontram à disposição daquele profissional que entende a realidade na qual está inserido e deseja fazer "melhor" e diferente".

5 “'...] absolutamente necessário que as instituições de ensino superior que oferecem curso de Direito à população quebrem os paradigmas do passado, por meio de uma atividade didática e educacional inovadora, capaz de ser compreendida pelo aluno contemporâneo e que possa, de fato, mudar a forma de atuação profissional que prevalece em nossos dias.” (GABRICH, 2010, p. 277).

6 "Construtivismo é uma das correntes teóricas empenhadas em explicar como a inteligência humana se desenvolve partindo do princípio de que o desenvolvimento da inteligência é determinado pelas ações mútuas entre o indivíduo e o meio. A ideia é que o homem não nasce inteligente, mas também não é passivo sob a influência do meio, isto é, ele responde aos estímulos externos agindo sobre eles para construir e organizar o seu próprioconhecimento, de forma cada vez mais elaborada. Na educação, trata-se de uma teoria a 7 respeito do aprendizado." (CONSTRUTIVISMO, 2015).

7 E imprescindível que o aluno se conscientize da necessidade de se esforçar. A meritocracia deve prevalecer, invertendo-se a lógica do menor esforço, presente em muitas instituições de ensino, traduzindo-se em comodismo por parte dos educandos. Inexiste relação direta de causa e efeito entre o ato de ensinar e o de aprendizagem. Ou seja, o ato de ensinar alguém não garante que este necessariamente aprendeu. 
Numa perspectiva construtivista, teoria que recebe melhor a proposta em questão, algumas dessas práticas podem ser representadas pelo emprego do design instrucional e do design de atividades de aprendizagem, de mídias interativas, da gamificação, de mapas mentais, do Lego serious play, do brainstorming, da aprendizagem baseada em problemas - PBL, da sala de aula invertida, das técnicas de apresentações curtas (TED e Pecha Kucha), dentre outras.

Dentre essas ferramentas, destaca-se o storytelling. Originada do plano das organizações, o uso da "arte de contar histórias" (storytelling) no ensino jurídico reflete muitas vezes uma característica muito própria do Direito: o espelho da sociedade em movimento e seu exemplo e contribuição para a construção do saber.

\section{STORYTELLING NO ENSINO JURÍDICO}

Pensar e repensar o ensino jurídico sob a ótica da inovação ${ }^{8}$ é uma necessidade premente nos tempos atuais, especialmente se forem considerados os novos perfis e interesses dos alunos, o pluralismo de ideias e o enorme fluxo gratuito de informações, especialmente por meio da internet. Diante dessa observação (constatação), surgem novas possibilidades representadas por práticas voltadas a uma maior integração entre educadores e educandos, de modo a prestigiar a expansão eficaz do saber nos ambientes de aprendizagem. O storytelling é uma delas.

De acordo com Alfredo Pires de Castro e James McSill, storytelling é um modelo de comunicação através do qual se conta uma estória utilizando técnicas específicas, organizadas em um processo consciente, que possibilita a articulação de informações em determinado contexto e com um fim desejado (CASTRO; MCSILL, 2013, p. 10).

8 Para Frederico de Andrade Gabrich: "na prática empresarial, todavia, o termo inovação assume diversos significados, podendo representar, ao mesmo tempo: a) fazer o novo; b) fazer diferente; c) surpreender; d) mudar; e) proporcionar novas experiências" (GABRICH, 2012, p. 20). Desse modo, ao expressar "prática empresarial", deve-se alinhar essa explanação às práticas organizacionais (educacionais), e dentro dessa perspectiva encontram-se as instituições de ensino, organizações voltadas à efervescência do saber, cuja inovação é quase que uma obrigação inerente às suas atividades e ao compromisso ético-social da qual são responsáveis (GABRICH, 2012). 
Esse modelo advém do campo das organizações e pode ser ilustrado pelas medidas (principalmente as de planejamento de marketing) adotadas pelas empresas, que, ao utilizarem essa técnica, objetivam incrementar planos de ação voltados a produtos, publicidade e desenvolvimento de equipes.

No entanto, esse não é um modelo limitado ao ambiente empresarial e de cunho meramente mercantilista. Paul J. Corney ${ }^{9}$, renomado e respeitado profissional da área de gestão, ao abordar o tema, considera "o uso de narrativas (storytelling) uma técnica muito poderosa e que não serve apenas para usar na gestão de conhecimento (GC) organizacional" (NEVES, 2012).

O referido manager remete a narrativa de histórias aos tempos de estudo e ilustra essa situação da seguinte maneira:

Todos se lembram do seu professor(a) preferido(a) e tenho certeza que eles eram bons porque contavam histórias que davam vida ao tópico em causa. $\mathrm{O}$ meu professor de Direito era brilhante ao descrever de forma humorística casos que ilustravamo Direito Penal. (NEVES, 2012).

Esse delineamento quanto às narrativas nas aulas de Direito Penal merece destaque, uma vez que esse ramo (assim como outros) fornece uma gama considerável de possibilidades de uso do storytelling, em especial no que tange à prática no Tribunal do Júri, em que são julgados os crimes dolosos contra a vida, e onde ocorrem acalorados debates, em um cenário onde surgem narrativas fáticas que auxiliam as pessoas envolvidas nessa dinâmica a formar seu convencimento.

Entretanto, o exemplo do Júri será retratado a seguir, em tópico específico. Desse modo, cabe retomar as particularidades do storytelling e de sua utilidade para o ensino jurídico.

Atualmente, ainda se fala pouco sobre este recurso estratégico de comunicação e interação, o storytelling. Apesar disso, ele já pode ser percebido em diversos espaços na sociedade e nas organizações, gerando novas e diferentes produções de sentido (MAGALHÃES, 2014, p. 1).

Gyslaine Avelar Matos descreve em sua obra alguns apontamentos sobre esse recurso que utiliza e que possui como característica as narrativas, citando CzarniawskaJoerges, para quem o storytelling é alvo de desconfiança. Segundo o mencionado autor:

\footnotetext{
9 Paul J. Corney é sócio-gerente na Sparknow, empresa britânica com grande tradição no uso de narrativas.
} 


\begin{abstract}
Alguns acadêmicos são reticentes sobre a tentativa de transformar as histórias em uma ferramenta de comunicação à disposição daqueles que já tem poder. Esses argumentam que as histórias inventadas ou fabricadas tendem a gerar antihistórias, provocando o cinismo, a desconfiança e o ridículo. (CZARNIAWSKA-JOERGES, 2004 apud MATOS, 2010, p. 14).
\end{abstract}

Nessa mesma linha, Chrisian Salmon também menciona as palavras de Lym Smith; para quem:

[...] cativantes, as histórias podem ser transformadas em mentiras ou em propaganda. Se as pessoas mentem para si mesmas relatando suas próprias histórias, propondo uma explicação tranquilizadora sobre os acontecimentos, podem também enganar, reduzindo as contradições e as complicações. (SMITH apud SALMON, 2008, p. 11, tradução livre)

Não se pode olvidar que qualquer recurso (educacional ou não), se "mal" utilizado ou se aplicado de modo deturpado e irresponsável, perde sua credibilidade, gerando consequências maléficas aos envolvidos na experiência, comprometendo sua eficácia e desagregando, em vez de trazer a contribuição pretendida.

No entanto, não se pode negar o uso de uma ferramenta ou recurso pelo "simples" fato de ela poder ser manipulada e mal utilizada. Deve-se sim, reconhecê-la, explorando e entendendo seus mecanismos para extrair todo seu potencial inovador e benéfico para o fim que se pretende com seu uso.

E aqueles que fazem uso ou pretendem utilizar novos métodos precisam se qualificar para este fim. No entanto, deve-se também partir da premissa de que prevalece o ato responsável e ético da pessoa que utiliza novas estratégias como as do storytellig, e não o contrário, duvidando da idoneidade desse profissional.

Com esse discernimento, Frederico de Andrade Gabrich assumiu o desafio de empregar $o$ storytelling no ensino jurídico e delineou os aspectos relevantes de uma utilização responsável e eficaz desse recurso.

$\mathrm{O}$ autor defende a arte de contar histórias ao expor que:

[...] as técnicas de ensino devem sempre permitir a criação e a manutenção de um círculo virtuoso de aprendizado e de motivação, que pode ser estabelecido por meio da conjunção de argumentos lógico-matemáticos, musicais e cinestésicos, e que podem muito bem ser aglutinados por meio das técnicas de storytelling. (GABRICH, 2015, p. 113). 
Verifica-se, portanto, a preocupação do autor quanto à utilização dessa ferramenta de modo que se estabeleça um ciclo virtuoso de aprendizado, de motivação, de modo a aglutinar argumentos transdisciplinares ${ }^{10}$ ao contexto.

A boa prática narrativa, o contar histórias, e o enquadramento dialógico do saber teórico aos fatos da vida, deve ocorrer de modo a interligar os destinatários do aprendizado para que possam contextualizar o que receberam e agir de forma crítico-reflexiva. Para que isso ocorra de modo eficaz, são necessários alguns requisitos.

Frederico de Andrade Gabrich (2015) elenca elementos fundamentais da narrativa produtiva no ensino, e entende que qualquer história exige uma descrição simples e objetiva, principalmente no que tange aos seguintes aspectos: quem, onde, quando, o quê, como, por quê.

Conforme visto anteriormente, no plano jurídico muitos profissionais já fazem uso do storytelling, seja em sala de aula, seja na prática advocatícia ou em qualquer outra atividade relacionada. Isso porque se percebe, nos arquétipos, a presença, em especial nas aulas de Direito

Penal, dos elementos inerentes ao ato de narrar para ensinar.

É o que pode ser constatado na ilustração doutrinária trazida por Rogério Greco. Ao ensinar sobre o elemento subjetivo na legítima defesa, elencado no art. 25 do Código Penal, o autor faz uso da seguinte narrativa:

Suponhamos que, agindo com animus necandi (vontade de matar alguém - dolo de matar), Alberto se dirige à residência de Pedro, seu inimigo, e atire nele no exato momento em que este brandia um punhal a fim de causar a morte de João, que se encontrava já prostrado e não tinha sido visto por Alberto. Se tirássemos uma fotografia dos fatos, sem analisar o elemento subjetivo de Alberto, diríamos que ele teria agido em situação de legítima defesa de terceiro, haja vista que, ao atirar em Pedro, acabou por salvar a vida de João.

Contudo, como Alberto não tinha conhecimento de que agia nessa condição, ou seja, não sabia que atuava na defesa de terceira pessoa, deverá responder pelo crime de homicídio, pois sua vontade não era dirigida a salvar alguém, mas, sim, a causar a morte de seu inimigo. (GRECO, 2009, p. 353).

10 “[...] a transdisciplinaridade não é linear e pressupõe a conjunção de todos os saberes, contextualizados a partir das necessidades reais das pessoas e da vida. Na transdisciplinaridade o pensar e o ensinar pressupõem a importância de todos os modos de conhecimento, de todas as culturas, religiões, ideias e ciências que convivem e se complementam continua e sistematicamente em vários níveis de realidade" (GABRICH, 2013, p. 13). 
Trata-se de uma história contextualizada, que respeita os elementos indicados acima por Gabrich, para uma prática responsável do storytelling. Quem? Alberto, Pedro e João. Onde? Residência de Pedro. Quando? Quando se dirigia à residência de Pedro. O quê? Um homicídio, e não uma legítima defesa. Como? Por meio de uma arma de fogo, um tiro. Por quê? Em razão de ser seu inimigo, e de ter o dolo, a vontade de matá-lo, e não de salvar João, ou de agir em legítima defesa deste.

Esse tipo de abordagem é bastante utilizada por docentes de Direito Penal, que em sala de aula, talvez involuntariamente, mas espontaneamente, acabam "inovando" e auxiliando no aprendizado dos educandos. Estes, por sua vez, por meio de narrativas como essa, têm facilitada a compreensão de um instituto complexo como o em questão.

Fato é que a narrativa, o ato de contar histórias, o uso do storytelling, seja qual for a denominação empregada, de algum modo já é realidade nas salas de aula e na rotina do operador do Direito Penal, e atualmente é empregada de forma mais técnica e eficaz; no entanto, é preciso evoluir!

Esse tipo de história consegue a atenção do educando e cria o envolvimento necessário de todos, de modo a otimizar o aprendizado. Daí que o meio acadêmico deveria utilizar mais esse recurso, inspirando-se no exemplo de prática do Tribunal do Júri. Os exemplos de diálogo entre a prática e a teoria fluem por uma via de mão dupla; é preciso reconhecê-los e observá- los de modo mais atento.

De acordo com Liliam Silva:

Exames do cérebro revelam que não só estimulam o nosso aparelho cerebral, mas alteram a forma como nos comportamos, pois produzimos oxitocina neuroquímica quando nos engajamos emocionalmente e intelectualmente em uma narrativa atraente. Histórias contadas presencialmente (storytelling) ou histórias contadas digitalmente (Digital Storytelling) são histórias que professores levam os seus alunos ao aprendizado. (SILVA, 2015).

Aplicar o storytelling como recurso didático no ensino jurídico é relevante para o aprendizado dos educandos, para a interação destes com o professor (e com os próprios educandos e a sociedade) e para as experiências de vida de cada um, porquanto permite criar um panorama dinâmico (e não estático), trazendo para a sala de aula os acontecimentos sociais intrínsecos à realidade dos fatos e da teoria jurídica, a fim de formar seres pensantes, com capacidade de contextualização e discernimento crítico-reflexivo. 
Essa aplicação não confronta a teoria construtivista. Pelo contrário, o modelo construtivista, associado a outros, permite ao professor, no uso do storytelling, por exemplo, atuar como facilitador da aprendizagem.

A relevância do storytelling para a aprendizagem é mais evidente quando se tem exemplos práticos, uma vez que a narrativa de histórias pode advir de construções não necessariamente verídicas. No caso do Tribunal do Júri, entretanto, pode-se dizer que se trata de um local que representa em sua plenitude o manejo dessa técnica de narrar, exemplo exógeno às salas de aula, merecedor de maior consideração, pois pode e deve contribuir para repensar o ensino jurídico atual e as ferramentas empregadas no ambiente acadêmico.

De qualquer maneira, o diálogo entre a prática e a teoria jurídica deve se dar contínua e permanentemente, contribuindo para a formação do ser atuante nessas duas esferas, cujos exemplos e experiências servem reciprocamente, e devem se comunicar, sendo esta uma exigência contemporânea do ensino e da profissão no Direito.

\section{AS PRÁTICAS DE STORYTELLING E O EXEMPLO DO JÚRI}

Ao (re)pensar o ensino jurídico contemporâneo sob uma ótica construtivista, averígua-se a necessidade de adoção de "novas" práticas de aprendizagem no ambiente voltado ao saber.

O storytelling surge como opção não somente para os educadores, mas também para os profissionais do Direito em exercício, que poderiam e deveriam utilizar mais essa ferramenta ao lecionarem e atuarem, respectivamente.

Essa concepção é defendida por Frederico de Andrade Gabrich, segundo o qual:

É absolutamente necessário, então, que os professores de todas as disciplinas dos cursos jurídicos e todos os profissionais que atuam nas diversas profissões jurídicas aprendam, ensinem e pratiquem o storytelling, para que a atividade profissional e a própria ciência do Direito possam realmente evoluir em uma sociedade cada vez mais pluralista, comunicativa e aberta. (GABRICH, 2015, p. 99). 
O Direito apresenta uma relação íntima de cunho prático-teórico ${ }^{11}$ a ser considerada e destacada. Gabrich menciona a necessidade de muitos dos profissionais que atuam nas diversas profissões jurídicas aprenderem, ensinarem e praticarem o storytelling. Essa situação de fato já ocorre, principalmente no Tribunal do Júri, no qual não é difícil observar a prática dessa metodologia de comunicação, de convencimento e de persuasão estratégica que precisa ser transportada às salas de aula de todas as disciplinas nos cursos de Direito.

O Tribunal do Júri, consagrado na Carta da República de 1988 (art. 5º XXXVIII), possui diversos elementos peculiares caracterizadores desse exemplo de representação popular no palco do Direito.

Órgão do Poder Judiciário, o Júri é competente para julgar os crimes dolosos contra a vida estabelecidos pela legislação penal, quais sejam: homicídio; feminicídio (ou femicídio); induzimento, instigação ou auxílio ao suicídio; infanticídio e aborto; todos elencados nos arts.121 a 128 do Código Penal, dentre outros eventualmente conexos.

Entretanto esmiuçar os dispositivos e a previsão normativa quanto ao Júri não é o propósito deste trabalho. Nesta pesquisa, aborda-se o instituto do Júri numa perspectiva voltada ao ensino jurídico, de modo a repensá-lo, para que as práticas (narrativas de histórias) efetivadas fora do âmbito acadêmico sirvam de exemplo para utilização neste.

Nesse sentido, vale destacar, o Tribunal do Júri é exemplo de aplicação real e efetiva desse modelo estratégico de comunicação, qual seja, do storytelling, que se caracteriza pela técnica de narrar histórias com poder de persuasão, de contextualização e de integração.

Quanto ao storytelling, importante apresentar as considerações de Alfredo Pires de Castro e James McSill, segundo os quais:

O Storytelling é a síntese do próprio processo de criação e compartilhamento de uma estória de uma determinada 'narrativa'. Contar estórias é a capacidade de descrever fatos encadeados numa sequência utilizando uma organização lógica e uma estrutura capaz de transmitir um determinado significado [...] (CASTRO; MCSILL, 2013, p.10).

11 Ao fazer referência à teoria e à prática no Direito, considera-se nesta pesquisa a teoria como sendo aquela ministrada em sala de aula, nos cursos de graduação e pós-graduação referentes à área jurídica. Por óbvio, existem disciplinas de ordem prática nos mencionados cursos. Todavia, o termo prática remete neste trabalho à atividade profissional desenvolvida pelo operador do Direito, fora do ambiente acadêmico. 
Seguindo essa linha de raciocínio, Helke Jamylle C.M. Neves, José Edir A. Martins Junior e Luiz Fernando C. Volpe apontam as peculiaridades no Júri, em especial as histórias reprodutoras dos fatos típicos, caracterizando a utilização do storytelling nesse cenário:

[...] no Tribunal do Júri, no momento dos debates, está presente a teatralização como interpretação informativa, indutora, a qual é peculiar a este Tribunal, pois lá os fatos são contados como estórias, quando for conveniente para o Advogado de defesa. (NEVES; MARTINS JUNIOR; VOLPE, 2012).

Essas histórias são apresentadas por meio de narrativas, uma das maiores, se não a maior particularidade desse método, aplicável não somente aos ambientes organizacionais (de onde se originou do ponto de vista estratégico) ou no campo educacional, mas também e principalmente no âmbito do Tribunal do Júri, onde a narração tem destaque. É o que reconhece Eliene Rodrigues de Oliveira, ao expor que:

No Tribunal do Júri, o texto compõe-se pelo trabalho dos operadores do direito. Mesmo tendo suas peculiaridades, é possível enxergar a narração como a sua grande forma. $\mathrm{O}$ enfoque, o fato criminoso; sua síntese, o conflito humano na sociedade. (OLIVEIRA, 2006, p. 4).

Nessa esteira apresenta-se a linguagem, elemento integrante de toda e qualquer narrativa, inclusive e principalmente no Júri. Ainda de acordo com a mesma autora:

\begin{abstract}
A linguagem no Tribunal do Júri revela nada menos que um discurso persuasivo, em que a oratória baseia-se precipuamente no "apelo emocional", a provocar piedade ou terror para convencimento de uma tese proposta. A possibilidade de interpretar o fato acontecido encontra-se no discurso oral, na forma narrativa. (OLIVEIRA, 2006, p. 7).
\end{abstract}

Fica evidente, então, que a linguagem representa o poder de convencimento (mas não apenas isso) que um agente tem sobre seus interlocutores ou ouvintes.

Ainda quanto ao convencimento no âmbito do Júri, Gabriel Chalita sustenta que:

O convencimento por meio da sedução é uma arte capaz de validar argumentos bastante variados. No caso do tribunal do júri, o núcleo do debate entre acusação e defesa é provar se o réu representa ou não um risco a sociedade; convencer o júri a decidir de uma ou de outra forma é o objetivo mais relevante no discurso de cada parte. (CHALITA, 2004, p. 6). 
Entretanto convencer não basta. O storytelling tem o condão não só de informar e/ou de convencer, pois vai além; a narrativa de histórias possibilita a persuasão!

Nesse sentido, de acordo com Frederico de Andrade Gabrich, [...] existem diferenças significativas entre as ações de informar, de convencer, e de persuadir; que precisam ser observadas por qualquer pessoa que pretende compreender e usar atualmente o storytelling [...]. (GABRICH, 2015, p. 107).

Segundo o autor, essas diferenças devem ser observadas por qualquer pessoa que pretenda compreender e utilizar o storytelling, incluindo-se, portanto e inclusive, os profissionais do Júri, que tanto fazem uso dessa ferramenta de comunicação.

Quanto à persuasão, Gabrich entende que esta:

[...] vai muito além da informação e do convencimento, pois implica levar alguém a mudar de atitude, a partir dos dados recebidos e das provas apresentadas pelo emissor. A persuasão começa com a informação, passa pelo convencimento, mas somente acontece de forma efetiva quando o receptor muda e age de acordo com a vontade e/ou com o desejo predeterminado pelo emissor em sua mensagem, de forma explícita ou subliminar. (GABRICH, 2015, p. 108).

Vale ressaltar, então, que a persuasão implica mudar e agir de acordo com a vontade e/ou o desejo predeterminado pelo emissor da mensagem, levando alguém a mudar de atitude, a partir dos dados recebidos e das provas apresentadas. Ora, não é exatamente esse o propósito maior da acusação e da defesa quando atuam no Tribunal do Júri? Fica ainda mais evidente o alinhamento da prática do storytelling persuasivo nesse cenário, servindo o Júri como exemplo de aplicação desse método essencialmente estratégico.

Por essa razão, as palavras de Helke Jamylle C.M. Neves, José Edir A. Martins Junior e Luiz Fernando C. Volpe representam fielmente o entendimento acolhido nesta pesquisa:

Tendo em vista que os atos realizados no Tribunal do Júri são extremamente técnicos e fáticos, cabe ao Promotor e ao advogado explicá-los aos jurados, e, para tanto, eles utilizam-se de muita argumentação e persuasão. (NEVES; MARTINS JUNIOR; VOLPE, 2012).

Ainda sob a ótica do Júri, o profissional que nele atua, seja representante do Ministério Público, assistente do parquet, defensor público ou advogado, em regra não utiliza a narrativa de histórias sem o devido planejamento estratégico (voltado a um objetivo). 
Ao adotar esse método de comunicação, esse profissional busca, estrategicamente, conhecer e aplicar as técnicas essenciais a uma boa explanação, capaz de informar, convencer e, principalmente, conforme visto, persuadir.

Não obstante, vale observar que toda técnica demanda preparo daquele que pretende executá-la; com o storytelling não é diferente, seja por parte dos professores no campo educacional, seja por parte dos operadores na prática jurídica profissional, em especial os atuantes no Júri (acusação e defesa).

Nesse sentido, José Manoel Moran entende que, no âmbito do magistério:

\begin{abstract}
As técnicas de comunicação também são importantes para o sucesso do professor. Um professor que fala bem, que conta histórias, que tem feeling para sentir o estado de ânimo da classe, que se adapta às circunstâncias, que sabe jogar com as metáforas, o humor, que usa as tecnologias adequadamente, sem dúvida consegue bons resultados com os alunos. Os alunos gostam de um professor que os surpreenda, que traga novidades, que varie suas técnicas e métodos de organizar o processo de ensino- aprendizagem. (MORAN, 2007, p. 80).
\end{abstract}

Esse professor desenhado por Moran possui as mesmas características do prático atuante no Júri, sendo este um exemplo fiel de usuário de narrativas, quando age de modo a contar histórias, a observar as circunstâncias, o humor e as peculiaridades inerentes ao contexto.

No entanto, parte considerável dos educadores não planeja suas explanações nem se preocupa em utilizar técnicas de comunicação capazes de inovar e de surpreender os alunos, de modo a possibilitar uma aprendizagem mais eficaz.

Contudo, existe uma relação de similitude entre o trabalho do educador e do prático do Júri; este, ao atuar no Tribunal, fazendo uso (correto e exponencial) do storytelling, é exemplo para o primeiro.

Também é possível verificar a semelhança do ambiente no Tribunal do Júri com o ambiente de sala de aula, no que tange à aplicabilidade dos recursos intrínsecos à narrativa de histórias.

A narrativa de histórias consiste num modelo cujos elementos encontram-se à disposição de todos os atores do cenário jurídico; evidenciando a relação umbilical entre teoria e prática no Direito ${ }^{12}$ O diálogo prático-jurídico já ocorre no ensino jurídico, em

\footnotetext{
12 "Direito é uma ciência que pode ser traduzida hoje pela conjunção de elementos fáticos, dos valores e das normas, multiplicados pela interpretação de todos esses fatores a partir de uma visão holística (disciplinar, interdisciplinar, multidisciplinar e transdisciplinar), sistemática e teleológica." (GABRICH, 2015, p. 97).
} 
especial no Direito Penal ensinado nas academias. A literatura referente a essa disciplina reúne narrativas dispostas na forma de exemplos (muitas vezes associados e alinhados a casos reais) relacionados aos institutos jurídicos que se pretende lecionar, repassados aos alunos pelos professores da área na forma de "contar histórias".

Não por acaso os educandos ficam fascinados e bastante interessados, em regra, nas aulas de Direito Penal e nas experiências ali relatadas. Infelizmente, nas outras disciplinas ministradas no ensino jurídico, de modo geral, os educadores não utilizam o storytelling como poderiam e deveriam, mitigando o potencial desse recurso comunicacional eficaz, como acontece no Tribunal do Júri, regularmente.

Neste, o ambiente é extremamente rico no que diz respeito às narrativas, tendo em vista que a contextualização organizada dos fatos, por parte de acusação (Ministério Público) e defesa, permite a melhor compreensão e posterior persuasão dos jurados.

Assim, tomando-se como exemplo o Tribunal do Júri, esse raciocínio deve ser entendido e levado de forma exógena, de fora das academias para dentro destas, invertendose a lógica que prevalece, a de que o saber teórico remete à prática posterior.

Constata-se que as técnicas utilizadas no plano teórico ou no plano prático constituem- se como exemplos recíprocos a serem utilizados nos dois espaços.

No entanto, o diálogo entre a teoria e a prática nem sempre ocorre de modo suficiente e aceitável. Ao repensar o ensino jurídico é preciso, portanto, estabelecer um elo entre o que ocorre dentro das salas de aula e fora delas, a fim de construir, estrategicamente, melhores resultados, sempre voltados à estruturação dos objetivos de todos os atores desse contexto.

\section{CONCLUSÃO}

Expondo a necessidade de (re)pensar o ensino jurídico contemporâneo, verificou-se a possibilidade e viabilidade de se adotar uma análise estratégica do Direito voltada para a estruturação dos objetivos das pessoas, das organizações e do Estado.

As metodologias utilizadas na transmissão e na construção do conhecimento (saber) são inúmeras. O processo de aprendizagem merece ser reequacionado, de modo a identificar práticas inovadoras mais adequadas ao contexto do ensino (jurídico) atual. 
Impreterível inovar no ambiente de aprendizagem. Para isso, instituições e profissionais da educação (jurídica, em especial) devem fazer uso de processos mais condizentes com as exigências e expectativas dos destinatários do saber, de modo a aplicálas simbioticamente, formando um ciclo virtuoso numa acepção cada vez mais construtivista e menos exclusivamente instrutivista.

O storytelling, prática que consiste na narrativa de histórias, representa um modelo voltado à contextualização, fática ou não, de determinada situação em que está inserido um conjunto de informações e saberes a serem distribuídos de modo sistemático. O uso dessa ferramenta promove uma relação direta e dialógica entre teoria e prática, permitindo a integração, participação e envolvimento dos educandos, possibilitando a eles uma formação crítico-reflexiva do exposto.

Trata-se de uma engenharia pedagógica aplicável a qualquer contexto de aprendizagem, por meio de métodos, técnicas e recursos voltados a uma abordagem sistemática, em que todos os envolvidos podem (devem) participar e contribuir para construção, repasse e absorção do saber.

Essa ferramenta de comunicação estratégica tem como seu exemplo jurídico prático o Tribunal do Júri, ambiente em que as narrativas estão presentes com todos os seus elementos, e cuja aplicação e eficácia são evidenciados na rotina de seus profissionais.

É imperioso que exemplos práticos como os do Júri sejam transportados, cada vez mais, para a sala de aula, de modo que o ensino jurídico possa dialogar com a prática jurídica, potencializando as experiências voltadas ao saber.

\section{REFERÊNCIAS}

ADAS, Eduardo; GALVÃO, Joni. Super apresentações: como vender ideias e conquistar audiências. São Paulo: Panda Books, 2011.

ALFARO, Norman José Solórzano. Experiência jurídica, experiência de aprendizagem: algumas abordagens pedagógicas para gerar aprendizagens significativas no Direito. Meritum: Revista de Direito da Universidade FUMEC, Belo Horizonte, v. 8, n. 2, p. 411 440, jul. 2013.

ALMEIDA, Nanci Aparecida de. Tecnologia na escola: abordagem pedagógica a abordagem técnica. São Paulo: Cengage Learning, 2015.

BONFIM, Edilson Mougenot. Júri: do inquérito ao plenário. São Paulo: Saraiva, 2012. 
BONFIM, Edilson Mougenot. No tribunal do júri: crimes emblemáticos, grandes

julgamentos. 5. ed. São Paulo: Saraiva, 2013.

CAMPOLINA, Inês Maria de Carvalho. O (re) significar da educação jurídica: a utilização dos instrumentos pedagógicos da aprendizagem baseada nas teorias da Emancipação Pedagógica - Aprendizagem Baseada em Problemas e Casos Práticos, do Letramento Acadêmico e da Flexibilidade Cognitiva. In: SEMINÁRIO NACIONAL SOBRE ENSINO JURÍDICO E FORMAÇÃO DOCENTE, 3., 2014, Belo Horizonte. Anais... Belo Horizonte: Universidade Federal de Minas Gerais / Faculdade de Direito, out. 2014. Disponível em:

<https://universobh.files.wordpress.com/2015/08/o-re-significar-da-educac3a7c3a3ojurc3addica-1.pdf>. Acesso em: 7 jan. 2016.

CASTRO, Alfredo Pires de; MCSILL, James. Storytelling para resultados: como usar estórias no ambiente empresarial. Rio de Janeiro: Qualitymark, 2013.

CHALITA, Gabriel. A sedução no discurso. 2. ed. São Paulo: Saraiva, 2004.

CONEXÃO. Notícias. O poder do storytelling. 23 out. 2014. Disponível em:

<http://www.conexao.com/fgv/noticias/3197/o-poder-do-storytelling>. Acesso em: 12 dez.

2015.

CONSTRUTIVISMO. In: WIKIPÉDIA. Disponível em:

<https://pt.wikipedia.org/wiki/Construtivismo>. Acesso em: 8 mar. 1999.

COSTA, Eduardo Moura da. A cisão entre ensino e aprendizagem na informática educativa:

uma análise do construtivismo e do construcionismo. In: JORNADA DO HISTEDBR, 11.,2013, Cascavel/PR. Anais... Cascavel/PR: 23 a 25 out. 2013. Disponível em:<http://www.histedbr.fe.unicamp.br/acer_histedbr/jornada/jornada11/artigos/5/artigo_si mposi o_5_786_eduardomcbr@yahoo.com.br.pdf>. Acesso em: 15 jan. 2016.

DIAS, Reinildes; ARRUDA, Climene; BAMBIRRA, Raquel. Aprender a aprender: metodologia para estudos autônomos. Belo Horizonte: UFMG, 2006.

DUARTE, Nancy. Ressonância: apresente histórias visuais que encantem o público. Rio de Janeiro: Alta Books, 2012.

FREIRE, Paulo. Pedagogia da autonomia: saberes necessários à prática educativa. 51. ed. São Paulo: Paz e Terra, 2015.

GABRICH, Frederico de Andrade. Análise estratégica do Direito. Belo Horizonte: Universidade FUMEC. Faculdade de Ciências Humanas, Sociais e da Saúde, 2010.

GABRICH, Frederico de Andrade. Arte, Storytelling e Direito. In: CONPEDI, 24., 2015, Aracaju/SE. Anais... Aracaju/SE: CONPEDI, 3 a 6 de junho de 2015. p. 97-120. Disponível em: <http://www.conpedi.org.br/publicacoes/c178h0tg/4d9nht62/30jwr8S8xBOn8E6o.pdf>. Acesso em: 29 dez. 2015.

GABRICH, Frederico de Andrade. Inovação no Direito. Belo Horizonte: Universidade Fumec - FCH, 2012. 
GABRICH, Frederico de Andrade. Transdisciplinaridade no ensino jurídico. Publica Direito.2013.Disponível em:

<http://www.publicadireito.com.br/artigos/?cod=57db7d68d5335b52>. Acesso em: 6 ago. 2015.

GABRIEL, Yannis. Storytelling in organizations: facts, fictions and fantasies. Oxford: University Press, 2000.

GRECO, Rogério. Curso de Direito Penal. 11. ed. Rio de Janeiro: Impetus, 2009.

LISBOA, Aleluia Heringer. Mobilizar para o saber. Pensar a Educação em Pauta, ano 3, n.95, 4 set. 2015.2 Disponível <ttp://www.pensaraeducacaoempauta.com/\#!aleluia-04set/c1wyi>. Acesso em: $12 \mathrm{dez}$. 2015.

MAGALHÃES, Anita Cristina Cardoso. Storytelling como recurso estratégico comunicacional: construindo narrativas no contexto das organizações. CONRERP/3 ${ }^{\mathbf{a}}$ Conselho Regional de Profissionais de Relações Públicas - $3^{\text {a }}$ Região, 2014. Disponível em: <http://www.conrerp3.org.br/wpcontent/uploads/2014/08/Artigo-Anita-_-Storytelling-como- $\quad$ recurso-estrat\%C3\%A9gicocomunicacional.pdf>. Acesso em: 7 jan. 2015.

MATOS, Gislayne Avelar. Storytelling: líderes narradores de histórias. Rio de Janeiro: Qualitymark, 2010.

MORAN, José Manoel. A aprendizagem de ser educador. In: MORAN, José Manoel. A educação que desejamos: Novos desafios e como chegar lá. 2. ed. Campinas, SP: Papirus, 2007. p. 74-81. Disponível em:

<http://www.eca.usp.br/prof/moran/site/textos/educacao_inovadora/aprend.pdf $>$. Acesso em: 31 jan. 2012.

MOURA, Paula. Construcionismo X Construtivismo. Pedagogia \& Educação, 12 out. 2010. Disponível em:

$<$ http://paulapedagogiafaced.blogspot.com.br/2010/10/construcionismo-Xconstrutivismo.html?m=1>. Acesso em: $12 \mathrm{dez} .2015$.

MUSSIO, Simone Cristina; VALIDÓRIO, Valéria Cristiane; MERLINI, Véra Maria Ferro. As novas tecnologias acopladas à educação: Reflexões sobre o ensino-aprendizagem no século XXI. Revista RETC, n. 14, p. 44-52, abr. 2014. Disponível em: <http://revistafatecjd.com.br/retc/index.php/RETC/article/view/127/pdf>. Acesso em: 15 jan. 2016.

NEVES, Ana. Entrevista com Paul Corney. Kmol - Gestão de Conhecimentos e Aprendizagem Organizacional, 20 jul. 2012. Disponível em: <http://kmol.pt/entrevistas/2012/07/20/paul- corney>. Acesso em: 7 jan. 2015.

NEVES, Helke Jamylle Conceição Moraes; MARTINS JUNIOR, José Edir Arruda; VOLPE, Luiz Fernando Cassilhas. Do discurso no Tribunal do Júri e a sua influência na decisão dos jurados. Judicare - Revista Eletrônica da Faculdade de Direito de Alta $\begin{array}{llllll}\text { Floresta, Edição Especial, } & \text { v. } & 3, & \text { n. } & 3,\end{array}$ Disponível em:

<http://judicare.com.br/index.php/judicare/article/view/43/135>. Acesso em: 29 dez. 2015.

NUCCI, Guilherme de Souza. Tribunal do júri. 4. ed. São Paulo: Revista dos Tribunais, 2013. 
OLIVEIRA, Eliene Rodrigues de. Teatralização do Tribunal do Júri - Palco x platéia: Diálogo entre o Direito e o teatro. Virtuajus, Belo Horizonte, PUCMG, v. 2, p. 1-15, 2006. Disponível em: <http://www.fmd.pucminas.br/Virtuajus/2_2006/Docentes/pdf/Eliene.pdf >. Acesso em: 15 dez. 2015.

SALMON, Christian. Storytelling, la machine à fabriquer des histories et à formatter les espirits. Paris: La Découverte, 2008.

SILVA, Liliam. Digital Storytelling: Histórias que ensinam. Educação a distancia.com, 18 set. 2015. Disponível em: <http://www.educacao-a-distancia.com/digital-storytelling/>. Acesso em: 12 dez. 2015.

VILLARI, Dominic R. Practical Storytelling: how to use stories to build strong business and personal relationships. Boston: Rhapado Publishing, 2008.

WERNECK, Hamilton. Como ensinar bem e avaliar melhor. Petrópolis: Vozes, 2012. 